\title{
Floating Microspheres Based Nizatidine Gastro Retentive Formulation to Control the Release of Drug
}

\author{
Deepika Rajpali $^{1}$ (D), Vandana Gupta ${ }^{1, *}$ (D)
}

1 Mittal Institute of Pharmacy, Opposite Bhopal Memorial Hospital \& Research Centre, Ayodhya Bypass Road, Navi Bagh, Karond, Bhopal-462038, M.P, India

* Correspondence: vandanargpv@ gmail.com;

Scopus Author ID 36850112900

Received: 20.06.2020; Revised: 4.07.2020; Accepted: 4.07.2020; Published: 7.07.2020

\begin{abstract}
Present research aimed at formulation development and characterization of the floating drug delivery system of Nizatidine, a H2-receptor antagonist, widely prescribed in gastric ulcers and duodenal ulcers. Nizatidine loaded floating microspheres were developed by the solvent diffusionevaporation method using polymers hydroxypropyl methylcellulose (HPMC) and microcrystalline cellulose (MCC) to prolong the gastric retention time of the drug for the therapeutic management of gastric disorders like ulcers. Further, the developed formulations were characterized for percentage yield, drug entrapment, floating behavior, shape and surface morphology, in vitro drug release, determination of particle size and Zeta potential, in vitro stability studies, and antimicrobial activity. The percentage yield of the different formulation was found to be a range of $75.65-81.25 \%$, drug entrapment efficacies of different formulations were in the range of $65.56-75.65 \% \mathrm{w} / \mathrm{w}$, formulation F4 of floating microsphere was found to be $178.5 \mathrm{~nm}$, Zeta potential of optimized formulation F4 of floating microsphere was found $-33.6 \mathrm{Mv}$, Surface morphology of formulation examines at two different magnification 55X which illustrate the smooth surface of Microspheres. The in vitro drug release pattern of Nizatidine loaded optimized floating microsphere was subjected to the goodness of fit test by linear regression analysis, and it was observed that ' $r$ ' values of microsphere were maximum for zero-order, i.e., 0.969 hence indicating drug release from formulations follow zero-order kinetics with non-fickian diffusion mechanism which in turn prolonged drug release. The antimicrobial activity of the optimized formulation showed clear fluid with no development of turbidity. It inferred better clearance from infection than plain drug solution at the same doses. Floating microspheres of Nizatidine as gastro retentive dosage forms precisely control the release rate of Nizatidine to a peculiar site and expedite an immense impact on health care.
\end{abstract}

Keywords: Floating drug delivery system; Gastro retentive formulation; Microcrystalline cellulose; Nizatidine; Ulcer.

(C) 2020 by the authors. This article is an open-access article distributed under the terms and conditions of the Creative Commons Attribution (CC BY) license (https://creativecommons.org/licenses/by/4.0/).

\section{Introduction}

An ulcer is a round or oval-shaped hole (also called parietal defect), 2 to $4 \mathrm{~cm}$ in diameter with perpendicular borders and a smooth base. A Peptic Ulcer, also known as the gastric or duodenal ulcer, is an ulcer affecting the gastrointestinal tract that is characteristically acidic and thus extremely painful. Contrast to the prevailing belief. Peptic ulcers occur more often in the duodenum, first part of the small intestine than in the stomach [1]. 
Nizatidine is a histamine $\mathrm{H} 2$ antagonist used to treat gastric and duodenal ulcers, Gastroesophageal reflux disease (GERD), and other gastrointestinal disorders. It acts by inhibiting the release of acid and pepsin into the stomach. Nizatidine inhibits acid production by reversibly competing with histamine for binding to $\mathrm{H} 2$ receptors on the basolateral membrane of parietal cells [2]. Nizatidine is administered as often in tablet, capsule, syrup, and injection, but the bioavailability is less. Hence to elevate the peptic ulcer pain, the present work comprises formulating Nizatidine as gastro-retentive floating microspheres since gastroretentive floating microspheres have come out as a competent means of controlled delivery of many drugs. The increasing refinement of delivery technology will ensure the development of an increasing number of gastro-retentive drug formulations to optimize the delivery of pharmaceuticals that exhibit low bioavailability and extensive first-pass metabolism. A gastric floating drug delivery system can use for drugs that are primarily absorbed in the duodenum and upper jejunum compartments. It can prolong retention times of formulations in the GIT, and thereby improve their oral bioavailability [3]. The control of gastrointestinal transit could be the focus of the present investigations, which in turn may consequence in new therapeutic possibilities with substantial benefits for patients in the future. Floating drug delivery can prolong the gastric retention of microspheres and thereby possibly improve the oral bioavailability of Nizatidine. Present studies have been compiled to optimize the formulation variables to achieve floating dosage forms $[4,5]$.

\section{Materials and Methods}

\subsection{Materials.}

Nizatidine was obtained as a gift sample from Zydus Cadila Healthcare (India). HPMC, MCC, Ethanol, and Dichloromethane were procured from DOW chemicals India. Polyvinyl alcohols, Sodium Hydroxide, Disodium hydrogen phosphate, Potassium dihydrogen phosphate, Sodium chloride, etc. were purchased from CDH India. All other chemicals and reagents used in this study were obtained commercially and were of analytical (AR) grade.

\subsection{Preparation of floating microsphere of Nizatidine.}

Floating microspheres loaded with Nizatidine were prepared by using a solvent diffusion-evaporation method using HPMC and MCC along with Polyethylene Glycol (PEG). A specified quantity of drug and polymer were dissolved in 1:1 ratio of a solvent system of ethanol and dichloromethane. This clear solution was poured slowly in a thin stream into the aqueous solution of $1 \%$ polyvinyl alcohol. The prepared emulsion was continuously stirred for $3 \mathrm{~h}$ with a speed of $500 \mathrm{rpm}$ at the temperature of $27 \pm 2^{\circ} \mathrm{C}$. The floating microspheres were collected by decantation, while the non-floating microspheres were discarded. The microspheres were dried overnight at $40 \pm 2^{\circ} \mathrm{C}$ and stored in desiccator [6].

\subsection{Characterization of floating microspheres.}

\subsubsection{Percentage $(\%)$ yield.}

The prepared floating microspheres were collected and weighed for various formulations. The measured weight was divided by the total amount of all non-volatile components which were used for the preparation of the microspheres. Each determination was made in triplicate. 


$$
\% \text { Yield }=\frac{\text { Actual weight of product }}{\text { Total weight of drug and polymer }} \times 100
$$

\subsubsection{Determination of entrapment efficiency.}

Ten mg of floating microspheres from all batches were accurately weighed and crushed. The powder of microspheres was dissolved in $10 \mathrm{~mL} 0.1 \mathrm{~N} \mathrm{HCl}$ and centrifuged at $1000 \mathrm{rpm}$. This supernatant solution is then filtered through Whatman filter paper No. 44. After filtration, from this solution, $0.1 \mathrm{~mL}$ was taken out and diluted up to $10 \mathrm{~mL}$ with $0.1 \mathrm{~N} \mathrm{HCl}$. The percentage of drug entrapment was calculated using the calibration curve method by extrapolation. The drug entrapment efficiency was calculated by the following equation:

$$
\% \text { Entrapment efficiency }=\frac{\text { Amount of drug present after centrifugation }}{\text { Total amount of drug added into the formulation }} \times 100
$$

Each determination was made in triplicate.

\subsubsection{Floating behavior.}

Ten $\mathrm{mg}$ of the floating microspheres were placed in $0.1 \mathrm{~N} \mathrm{HCl}(100 \mathrm{~mL})$. The mixture was stirred at $100 \mathrm{rpm}$ in a magnetic stirrer. After $10 \mathrm{~h}$, the layer of the buoyant microsphere was pipetted and separated by filtration. Particles in the sinking particulate layer were separated by filtration. Particles of both types were dried in desiccators until a constant weight was obtained. Both the fractions of microspheres were weighed, and buoyancy was determined by the weight ratio of floating particles to the sum of floating and sinking particles [7]. Each determination was made in triplicate.

$$
\% \text { Buoyancy }=\frac{\text { Final weight-Initial weight }}{\text { Initial weight }} \times 100
$$

\subsubsection{In-vitro release studies.}

The drug release studies from floating microspheres were carried out using the USP type II (ELECTROLAB, India) dissolution test apparatus. A weighed amount of floating microspheres equivalent to $100 \mathrm{mg}$ drug were dispersed in $900 \mathrm{~mL}$ of $0.1 \mathrm{~N} \mathrm{HCI}(\mathrm{pH}=1.2)$ maintained at $37 \pm 0.5^{\circ} \mathrm{C}$ and stirred at $55 \mathrm{rpm}$. One $\mathrm{mL}$ sample was withdrawn at predetermined intervals and filtered. An equal volume of dissolution medium was replaced in the vessel after each withdrawal to maintain sink condition. The collected samples analyzed spectrophotometrically at $\lambda \max (322 \mathrm{~nm})$ to determine the concentration of drug present in the dissolution medium. Each determination was made in triplicate.

\subsubsection{Drug release kinetic data analysis.}

Several kinetic models have been proposed to describe the release characteristics of a drug from a matrix. The following three equations are commonly used because of their simplicity and applicability. The zero-order model equation (Plotted as cumulative percentage of drug released $v s$ time); Higuchi's square-root equation (Plotted as cumulative percentage of drug released vs square root of time); and Korsemeyer-Peppas equation (Plotted as Log cumulative percentage of drug released $v s$ Log time). 
To study the release kinetics of Nizatidine from the floating microspheres, the release data were fitted to these equations:

Zero-order equation: When a graph of the cumulative percentage of the drug released from the matrix against time is plotted, the zero-order release is linear in such a plot, indicating that the release rate is independent of concentration.

$$
\mathrm{Q}_{\mathrm{t}}=\mathrm{k}_{0} . \mathrm{t}
$$

Where $\mathrm{Q}_{\mathrm{t}}$ is the percentage of drug released at time $\mathrm{t}$ and $\mathrm{k}_{0}$ is the release rate constant; First-order equation

$$
\text { In }\left(100-\mathrm{Q}_{\mathrm{t}}\right)=\text { In } 100-\mathrm{k}_{\mathrm{I} . \mathrm{t}}
$$

Where $\mathrm{k}_{\mathrm{I}}$ is the release rate constant;

Higuchi's equation

$$
\mathrm{Q}_{\mathrm{t}}=\mathrm{kH} \cdot \mathrm{t}^{\mathrm{t} / 2}
$$

Where $\mathrm{K}_{\mathrm{H}}$ is the Higuchi release rate constant

Korsmeyer-Peppas

The curves plotted may have different slopes, and hence it becomes difficult to exactly pin-point which curve follows perfect zero-order release kinetics. Therefore, to confirm the kinetics of drug release, data were also analyzed using Korsemeyer's equation.

$$
\mathrm{Q}_{\mathrm{t}} / \mathrm{Q}_{\infty}=\mathrm{kKP.t}^{\mathrm{n}}
$$

Where $\mathrm{Q}_{t} / \mathrm{Q}_{\infty}$ is the fraction of drug released at time $\mathrm{t}$, $\mathrm{k}_{\mathrm{KP}}$ a constant compromising the structural and geometric characteristics of the system, and $n$ is the release exponent.

The slope of the linear curve gives the ' $n$ ' value. Peppas stated that the above equation could adequately describe the release of solutes from slabs, spheres, cylinders, and discs, regardless of the release mechanism. The value of ' $n$ ' gives an indication of the release mechanism. When $\mathrm{n}=1$, the release rate is independent of time (typical zero-order release / case II transport); $\mathrm{n}=0.5$ for Fickian release (diffusion/ case I transport); and when $0.5<\mathrm{n}<$ 1, anomalous (non-Fickian or coupled diffusion/ relaxation) are implicated. Lastly, when $\mathrm{n}>$ 1.0, super case II transport is apparent. The ' $n$ ' is the slope value of the $\log M_{t} / M_{\infty} v s . \log$ time curve.

\subsubsection{Measurement of mean particle size.}

The mean size of the floating microsphere was determined by Photon Correlation Spectroscopy (PCS) on a submicron particle size analyzer (Horiba LA-960, Germany) at a scattering angle of $90^{\circ}$. A sample $(0.5 \mathrm{mg})$ of the floating microspheres suspended in $5 \mathrm{~mL}$ of distilled water was used for the measurement. Each determination was made in triplicate.

\subsubsection{Determination of Zeta potential.}

The Zeta potential of the drug-loaded microspheres was measured on a Zeta Sizer (Horiba LA-960, Germany) by determining the electrophoretic mobility in a micro electrophoresis flow cell. All the samples were measured in water at $25^{\circ} \mathrm{C}$ in triplicate. Each determination was made in triplicate.

2.3.8. Shape and surface morphology by scanning electron microscopy (SEM).

Optimized formulation (Batch: F4), which showed the best response, was examined for surface morphology and shape using a scanning electron microscope (Jeol-6000, Japan). The 
sample was fixed on carbon tape, and fine gold sputtering was applied in a high vacuum evaporator. The acceleration voltage was set at $10 \mathrm{KV}$ during scanning. Microphotographs were taken on different magnification, and higher magnification (200X) was used for surface morphology.

2.3.9. Stability studies for optimized formulation.

According to ICH guidelines, 3 months accelerated stability study at $40 \pm 2^{\circ} \mathrm{C}$, and $75 \pm 5 \%$ was carried out for optimized formulations (Batch: F4). Optimized drug formulation was evaluated for appearance, size, and buoyant properties before and after 3 months of storage at $40 \pm 2{ }^{\circ} \mathrm{C} \& 75 \pm 5 \% \mathrm{RH}$. Each determination was made in triplicate.

\subsubsection{Antimicrobial activity.}

The antimicrobial activity was carried out on the basis of the inhibition zone. The optimized nizatidine-loaded floating microspheres, plain drug solution, and 10\% DMSO were investigated at various time intervals in the isolated H.pylori bacterial strain up to $24 \mathrm{~h}$.

\subsubsection{Colony selection.}

Colonies of $\mathrm{H}$. pylori were inoculated on an agar plate and incubated at $37^{\circ} \mathrm{C}$ for 3 days under Bacteriological Incubator (Rolex, India) [8].

\subsubsection{Screening of formulations for anti-H. pylori activity.}

Antimicrobial activities of various formulations were assessed by the agar well diffusion method. Antimicrobial susceptibility was tested on solid media in Petri dishes as per the previously reported method [9]. Concisely, H.pylori inoculated onto agar. The inoculate was evenly spread on the plate from subcultures of $H$. pylori by sterile cotton swab and let on to dry for 5-8 min. Wells ( $6 \mathrm{~mm}$ in diameter) were punched into the agar using a sterile stainless steel borer and filled with $50 \mu \mathrm{L}$ of the formulation at $100 \mathrm{mg} / \mathrm{mL}$. DMSO (10\%) acted as a negative control, and $10 \mu \mathrm{g} / \mathrm{mL}$ plain drug solution was used as positive control included in all experiments, respectively. The plates were incubated under microaerophilic conditions GasPak TM Anaerobic System (Oxoid) at $37^{\circ} \mathrm{C}$ for 24 hours, and the diameters of zones of inhibition were recorded at various time intervals. The experiment was repeated and means zones recorded.

\section{Results and Discussion}

\subsection{Formulation of floating microsphere of Nizatidine.}

The floating microspheres are gastro retentive drug delivery systems. In present work, it was prepared by the method of non-effervescent approach. Floating microspheres are, in a strict sense, empty spherical particles without a core. The property of prepared floating microspheres is claimed to delayed transit through the stomach. The drug is released slowly at the desired rate, resulting in increased gastric retention with reduced fluctuations in plasma drug concentration. Floating microspheres are hollow microspheres. Solvents: ethanol and dichloromethane used in the preparation are imparted in floating properties of the system by diffusion and evaporation methods to create the hollow inner core (Figure 1). 


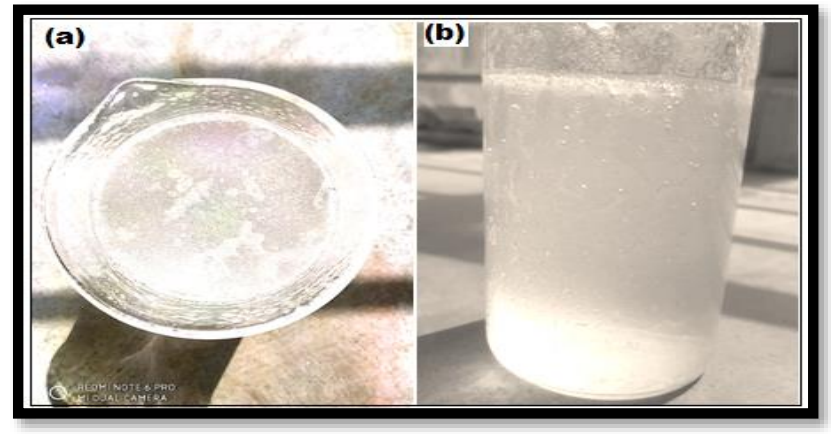

Figure 1. Images of Nizatidine loaded floating microspheres after preparation: (a) Top view and: (b) Front view.

\subsection{Percentage (\%) yield.}

The percentage yield of the different formulation was determined by weighing the microspheres after drying. The percentage yield of the various formulations was found to be in the range of $75.65 \pm 0.56 \%-81.25 \pm 0.14 \%$ (Table 1). It was quite high, and it may be achieved due to optimum viscosity of the drug-polymer solution and ultimately increases the production yield of microspheres. Further, the yield of the microsphere is also increasing with the increase in the concentration of the polymer solution during formulation development $[10,11]$.

Table 1. Results of Percentage Yield, Drug Entrapment, Percentage Buoyancy, and Floating Lag Time of various Batches of Nizatidine loaded Floating Microspheres.

\begin{tabular}{l|l|l|l|l|l} 
S. No. & Batch Code & $\begin{array}{l}\boldsymbol{\%} \text { Yield } \\
(\boldsymbol{w} / \boldsymbol{w})\end{array}$ & $\begin{array}{l}\boldsymbol{\%} \text { Efficiency }(\boldsymbol{w} / \boldsymbol{w}) \\
\text { Entrapment }\end{array}$ & $\begin{array}{l}\boldsymbol{\%} \text { Buoyancy } \\
(\boldsymbol{w} / \boldsymbol{w})\end{array}$ & $\begin{array}{l}\text { Floating } \\
\text { Time }(\mathbf{s})\end{array}$ \\
\hline 1 & F-1 & $78.98 \pm 0.25$ & $68.60 \pm 0.25$ & $65.56 \pm 0.45$ & $45 \pm 1.50$ \\
\hline 2 & F-2 & $79.98 \pm 0.12$ & $70.25 \pm 0.56$ & $68.98 \pm 0.65$ & $35 \pm 0.50$ \\
\hline 3 & F-3 & $76.56 \pm 0.36$ & $69.65 \pm 0.47$ & $62.23 \pm 0.25$ & $40 \pm 1.00$ \\
\hline 4 & F-4 & $81.25 \pm 0.14$ & $75.65 \pm 0.58$ & $75.65 \pm 0.45$ & $28 \pm 0.50$ \\
\hline 5 & F-5 & $76.56 \pm 0.25$ & $70.12 \pm 0.65$ & $70.12 \pm 0.65$ & $33 \pm 1.00$ \\
\hline 6 & F-6 & $75.65 \pm 0.56$ & $65.56 \pm 0.84$ & $68.45 \pm 0.21$ & $45 \pm 2.00$
\end{tabular}

Results are represented as mean $\pm \operatorname{SD}(n=3)$

\subsection{Drug entrapment.}

The percentage drug entrapment efficiency of various formulations was found to be in the range of $65.56 \pm 0.84 \%-75.65 \pm 0.58 \% w / w$ (Table 1). Generally, Encapsulation efficiency increases with increasing polymer concentration [12-14]. In the present investigation, the encapsulation efficiency was found to be maximum $(75.65 \pm 0.58 \% \mathrm{w} / \mathrm{w})$ for the optimized formulation (Batch: F-4) as the amount of polymer (HPMC) increased from 100mg to $150 \mathrm{mg}$ during formulation optimization.

\subsection{Percentage Buoyancy and floating lag time of floating microsphere.}

The formulation F4 has shown the highest percentage buoyancy with minimum floating lag time (Table 1). Buoyancy in percentage was found to be in the range of $62.23 \pm 0.25 \%$ to $75.65 \pm 0.45 \%$. In general, the presence of Polyethylene Glycol 400 (PEG 400), there was an increase in the buoyancy percentage [15]. The presence of MCC, along with polyethylene glycol, might be act as a pore-forming agent to induce buoyancy [16-18]. The time required for the microspheres to rise to the surface and float was determined as floating lag time. Incorporation of PEG 400 as a pore-forming agent or surfactant in the formulation can lead to the porous structure of the microspheres. 


\subsection{In vitro drug release study of Nizatidine loaded microsphere.}

The in vitro drug release data of the optimized formulation was subjected to the goodness of fit test by linear regression analysis according to zero-order and first-order kinetic equation in order to determine the mechanism of drug release. The regression coefficient $\left(r^{2}\right)$ values (Table 2) obtained were found to be better for the first-order plot (Figure 2) compared to zero-order (Figure 3) drug release, indicating that the drug release was described better with first-order release kinetics. The floating microsphere formulations were able to sustain the release (Figure 4) of drugs due to high polymer content, probably because of drug binding to the polymer (Table 3). Further, the kinetic release data indicated that the mechanism of drug release was diffusion controlled [19-21].

Table 2. Comparative study of the regression coefficient for the selection of optimized Formulation (Batch:F-4).

\begin{tabular}{l|l}
\multicolumn{2}{c}{ Release Kinetics } \\
\hline $\mathrm{r}^{2}$ & Microsphere
\end{tabular}

\section{Zero-order}

0.969
First-order

0.797

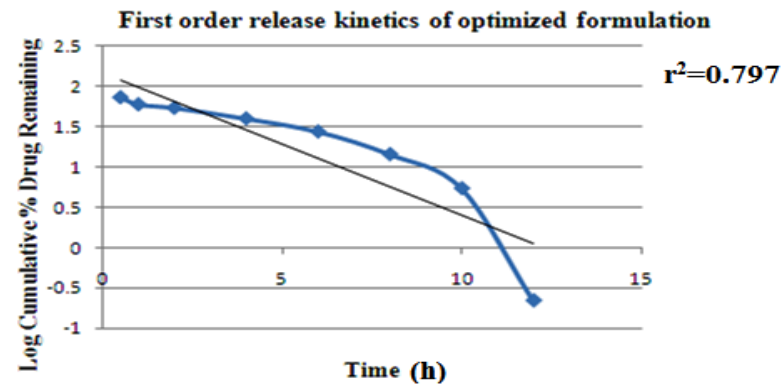

Figure 2. First-order release kinetics graph of optimized formulation (Batch: F-4).

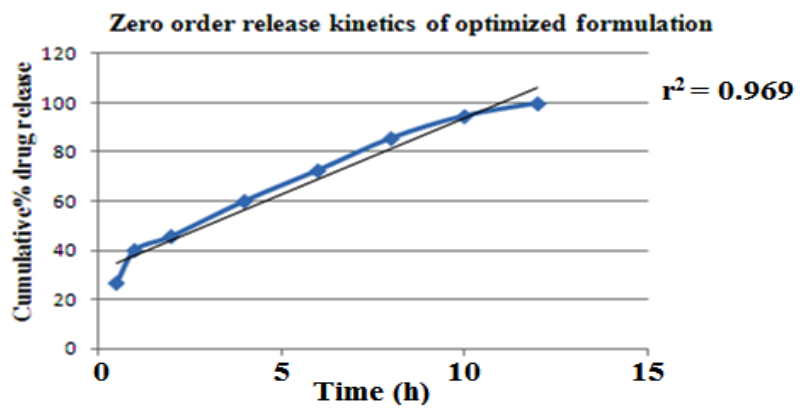

Figure 3. Zero-order release kinetics graph of optimized formulation (Batch: F-4).

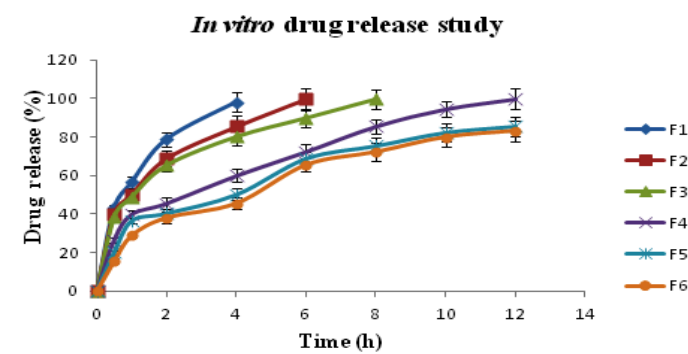

Figure 4. In vitro release of Nizatidine from various floating microsphere formulations (Batches: F-1 to F-6).

Values are expressed as mean \pm standard deviation $(n=3)$.

Table 3. Release Kinetics of optimized formulation of Nizatidine loaded floating microsphere (Batch: F-4)

\begin{tabular}{l|l|l|l|l|l|l|}
$\begin{array}{l}\text { Time } \\
\text { (h) }\end{array}$ & $\begin{array}{l}\text { Square Root } \\
\text { of Time(h) }\end{array}$ & $\begin{array}{l}\text { Log } \\
\text { Time }\end{array}$ & $\begin{array}{l}\text { Cumulative\% } \\
\text { Drug Release }\end{array}$ & $\begin{array}{l}\text { Log } \\
\text { Cumulative \% } \\
\text { Drug Released }\end{array}$ & $\begin{array}{l}\text { Cumulative \% } \\
\text { Drug } \\
\text { Remaining }\end{array}$ & $\begin{array}{l}\text { Log Cumulative } \\
\text { \%emaining } \\
\text { Drug }\end{array}$ \\
\hline $\mathbf{0 . 5}$ & 0.707 & -0.301 & 26.65 & 1.426 & 73.35 & 1.865 \\
\hline $\mathbf{1}$ & 1.000 & 0.000 & 39.98 & 1.602 & 60.02 & 1.778
\end{tabular}




\begin{tabular}{l|l|l|l|l|l|l}
\hline $\begin{array}{l}\text { Time } \\
\text { (h) }\end{array}$ & $\begin{array}{l}\text { Square Root } \\
\text { of Time(h) })^{\mathbf{1 2}}\end{array}$ & $\begin{array}{l}\text { Log } \\
\text { Time }\end{array}$ & $\begin{array}{l}\text { Cumulative\% } \\
\text { Drug Release }\end{array}$ & $\begin{array}{l}\text { Log } \\
\text { Cumulative \% } \\
\text { Drug Released }\end{array}$ & $\begin{array}{l}\text { Cumulative \% } \\
\text { Drug } \\
\text { Remaining }\end{array}$ & $\begin{array}{l}\text { Log } \\
\text { \% } \\
\text { Remaining }\end{array}$ \\
\hline $\mathbf{2}$ & 1.414 & 0.301 & 45.65 & 1.659 & 54.35 & 1.735 \\
\hline $\mathbf{4}$ & 2.000 & 0.602 & 59.98 & 1.778 & 40.02 & 1.602 \\
\hline $\mathbf{6}$ & 2.449 & 0.778 & 72.45 & 1.860 & 27.55 & 1.440 \\
\hline $\mathbf{8}$ & 2.828 & 0.903 & 85.56 & 1.932 & 14.44 & 1.160 \\
\hline $\mathbf{1 0}$ & 3.162 & 1.000 & 94.56 & 1.976 & 5.44 & 0.736 \\
\hline $\mathbf{1 2}$ & 3.464 & 1.079 & 99.78 & 1.999 & 0.22 & -0.658
\end{tabular}

3.6. Particle size analysis.

The particle size of floating microspheres somewhat different among the various formulations due to variation in the composition of formulations. The results of the measurement of the mean particle size of optimized formulation (Batch: F4) of the floating microsphere was found to be $178.5 \mathrm{~nm}$. The particle size of the microspheres was found to be in the nano range (Figure 5). This is because the viscosity of the formulation is optimum, which in turn reduces the interfacial tension, and finally increases in the stirring efficiency, which results in reduced particle size.

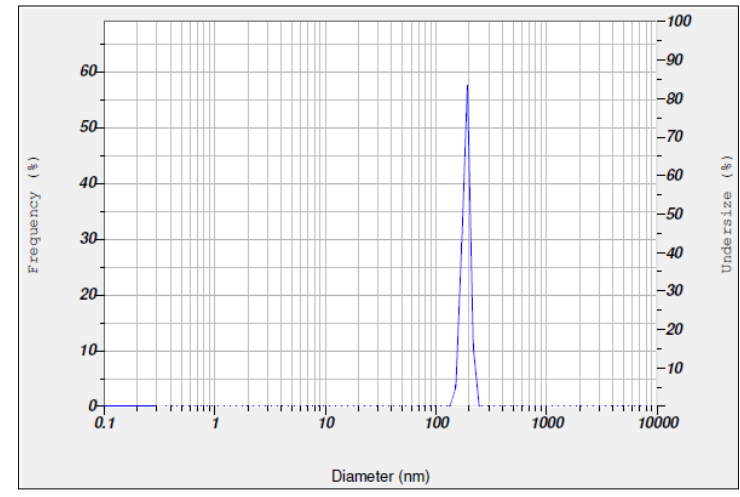

Figure 5. Particle size data of optimized microsphere formulation (Batch: F-4).

\subsection{Determination of Zeta potential.}

Zeta potential of optimized formulation (Batch: F4) of the floating microsphere was found to be $-33.6 \mathrm{mV}$ (Figure 6).

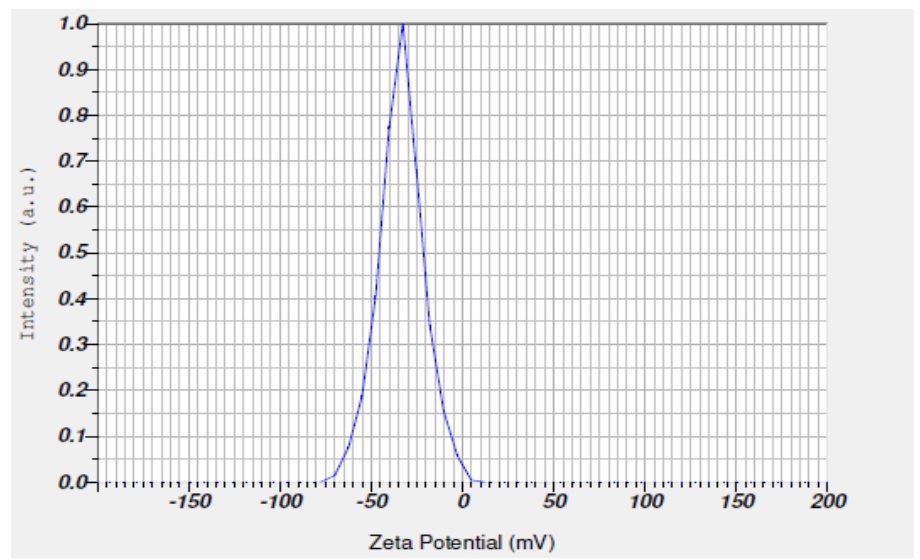

Figure 6. Zeta potential data of optimized microsphere formulation (Batch: F-4).

The results showed favorable zeta potential with a value of $-33.6 \mathrm{mV}$. This result evident that the interaction between the polymers: HPMC and MCC may impact the Zeta potential. Choosing a sufficient amount of HPMC in comparison with the amount of MCC can 
cause electrostatic repulsion between floating microspheres to provide enough surface charges for stabilization of the formulation. PEG also shows negative zeta potential around $\mathrm{pH} 7$ and impart in formulation stability. Zeta potential represents the surface charge of the system, which may give an indication of the possible stability of the system [22-24]. Zeta potential is the potential surrounding the spheres at the plane of shear. The repulsive electrostatic interactions between similarly charged microspheres do not allow them to get closer, which hinders aggregation and ultimately favor the system stability [25, 26].

\subsection{Scanning electronic microscopy.}

Shape and surface characteristic of optimized Nizatidine floating microspheres examine by Scanning Electron Microscopy (SEM). The SEM image of floating microspheres showed a smooth surface, spherical, balloon-like, and elongated shapes and single lamella in the structure (Figure 7).

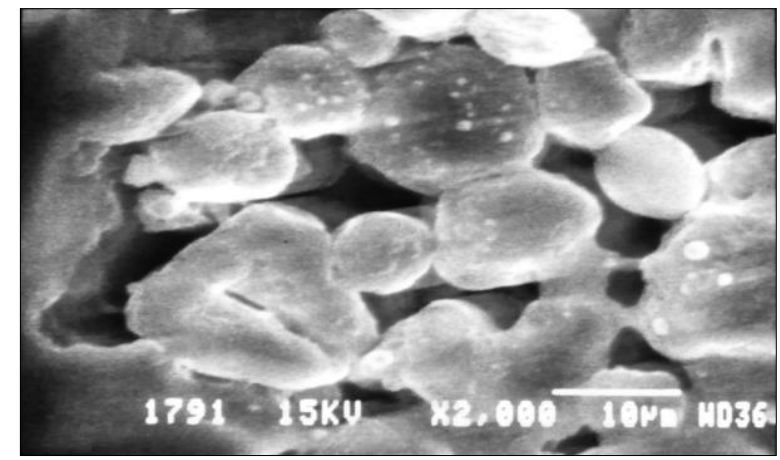

Figure 7. Scanning electronic microscopy image of optimized microsphere formulation (Batch: F-4).

\subsection{Stability studies for optimized formulation.}

According to ICH guidelines [27, 28], 3 months accelerated stability study at $40 \pm 2^{\circ} \mathrm{c}$, and $75 \pm 5 \%$ was carried out for optimized formulations (F4). It showed negligible change over time for parameters like appearance, drug content, dissolution, and assay, etc. No significant difference observed in the drug content between initial and formulations stored at $40 \pm 2^{\circ} \mathrm{c} \&$ $75 \pm 5 \%$ RH for 3 months.

\subsection{Antimicrobial Activity.}

The antimicrobial activity of the optimized drug-loaded, plain drug, and 10\% DMSO were investigated at various time intervals in the isolated H.pylori bacterial strain up to $24 \mathrm{~h}$. Plain drug and optimized formulation of the Nizatidine floating microspheres (Batch: F4) were taken containing drug equivalent to $30 \mu \mathrm{g} / \mathrm{mL}$. Optimized Nizatidine formulation (Batch: F4) shows a greater zone of inhibition $(30 \mathrm{~mm}, 35 \mathrm{~mm}$, and $40 \mathrm{~mm}$ ) against $\mathrm{H}$. Pylori after $6 \mathrm{~h}, 12 \mathrm{~h}$, and $24 \mathrm{~h}$, respectively. At the same time, plain drug solution inhibited a $40 \mathrm{~mm}$ zone at $6 \mathrm{~h}$ of the studies. Ten percent DMSO as the negative controls did not show any inhibition zones of the test strain. Continuing the incubation of $H$. pylori up to $24 \mathrm{~h}$, the optimized formulation (F4) was eradicated hundred percent growth of the H. pylori.

This was due to the controlled delivery of Nizatidine from the floating microspheres and the long time exposure of the microorganism, which resulted in the complete clearance of $H$. pylori [29, 30]. 


\section{Conclusions}

Floating microspheres of Nizatidine as a gastro retentive drug delivery system specifically control the release rate of drugs to a particular site and facilitate an enormous effect on health care. The anti H. pylori study showed good antimicrobial activity of optimized Nizatidine loaded floating microspheres (Batch: F4). From the results of the present investigation, one can conclude that floating systems provide tremendous opportunities in the designing of new controlled and delayed-release oral formulations, thus spanning the frontier of revolutionary pharmaceutical development.

\section{Funding}

This research received no external funding.

\section{Acknowledgments}

Authors are grateful to the Mittal Institute of Pharmacy, Bhopal, for providing necessary facilities and materials for the successful completion of research work.

\section{Conflicts of Interest}

The authors declare no conflict of interest.

\section{References}

1. Suradkar, P.; Mishra, R.; Nandgude, T. Overview on Trends in Development of Gastroretentive Drug Delivery System. Research Journal of Pharmacy and Technology 2019, 12, 5633-5640, http://dx.doi.org/10.5958/0974-360X.2019.00975.2.

2. Karan, S.; Choudhury, H.; Chakra, B.K.; Chatterjee, T.K. Polymeric microsphere formulation for Colon targeted delivery of 5-fluorouracil using biocompatible natural gum Katira. Asian Pacific Journal of Cancer Prevention 2019, 20, 2181-2194, https://dx.doi.org/10.31557\%2FAPJCP.2019.20.7.2181.

3. Mandal, U.K.; Chatterjee, B.; Senjoti, F.G. Gastro-Retentive Drug Delivery Systems and their In vivo Success:A Recent Update. Asian Journal of Pharmaceutical Sciences 2016, 11, 575-584, https://doi.org/10.1016/j.ajps.2016.04.007.

4. Tripathi, J.; Thapa, P.; Maharjan, R.; Jeong, S.H. Current State and Future Perspectives on Gastroretentive Drug Delivery Systems. Pharmaceutics 2019, 11, https://dx.doi.org/10.3390\%2Fpharmaceutics11040193.

5. Srivastava, A.; Shukla, R.; Sharma, K.; Jain, H.; Meshram, D.B. Microballoons: A Gastro Retentive Drug Delivery System. Journal of Drug Delivery and Therapeutics 2019, 9, 625-630, https://doi.org/10.22270/jddt.v9i4-s.3274.

6. Kesavan, J.; Schepers, D.; McFarland, A.R. Sampling and Retention Efficiencies of Batch-Type LiquidBased Bioaerosol Samplers. Aerosol Science and Technology 2010, 44, 817-829, https://doi.org/10.1080/02786826.2010.497513.

7. Amin, M.L.; Jesmeen, T.; Sutradhar, K.B.; Mannan, M.A. Development and In vitro Evaluation of Diclofenac Sodium loaded Mucoadhesive Microsphere with Natural Gum for Sustained Delivery. Current Drug Delivery 2013, 10, 765-770, https://doi.org/10.2174/15672018113109990054.

8. Westblom, T.U. Laboratory diagnosis and handling of Helicobacter pylori. In: Helicobacter pylori. in peptic ulceration and gastritis. Marshall, B.J.; McCallum, R.W.; Guerrant, R.L. editors. Boston: Blackwell Scientific; 1991, pp. 81-91.

9. $\quad$ Boyanova, L.; Gergova, G.; Nikolov, R.; Derejian, S.; Lazarova, E.; Katsarov, N.; Mitov, I.; Krastev, Z. Activity of Bulgarian Propolis against 94 Helicobacter Pylori Strains In vitro by Agar-well diffusion, Agar dilution and Disc diffusion Method. Journal of Medical Biology 2005, 54, 481-483, https://doi.org/10.1099/jmm.0.45880-0.

10. Dhankar, V.; Garg, G.; Dhamija, K.; Awasthi, R. Preparation, Characterization and Evaluation of Ranitidine Hydrochloride loaded Mucoadhesive Microspheres. Polimery w medycynie 2014, 44, 75-81.

11. Kotagale, N.R.; Parkhe, A.P.; Jumde, A.B.; Khandelwal, H.M.; Umekar, M.J. Ranitidine HydrochlorideLoaded Ethyl Cellulose and Eudragit RS 100 Buoyant Microspheres: Effect of pH Modifiers. Indian Journal of Pharmaceutical Sciences 2011, 73, 626-633, https://dx.doi.org/10.4103\%2F0250-474X.100236. 
12. Ota, A.; Istenic, K.; Skrt, M.; Segatin, N.; Znidarsic, N.; Kogej, K.; Ulrih, N.P. Encapsulation of Pantothenic Acid into Liposomes and into Alginate or Alginate-Pectin Microparticles Loaded with Liposomes. Journal of Food Engineering 2018, 229, 21-31, https://doi.org/10.1016/j.jfoodeng.2017.06.036.

13. Dehcheshmeh, M.A.; Fathi, M. Production of Core-Shell Nanofibers from Zein and Tragacanth for Encapsulation of Saffron Extract. International journal of biological macromolecules 2019, 122, 272-279, https://doi.org/10.1016/j.ijbiomac.2018.10.176.

14. Cheng, S.Y.; Akindoyo, J.O.; Jaafar, M.; Hamid, Z.A.A. Effect of Formulation Variables on the Performance of Doxycycline-Loaded PLA Microsphere. Arabian Journal for Science and Engineering 2020, https://doi.org/10.1007/s13369-020-04592-6.

15. Farooq, S.M.; Sunaina, S.; Rao, M.; Venkatesh, P.; Hepcykalarani, D.; Preama, R. Floating Drug Delivery Systems: An updated Review. Asian Journal of Pharmaceutical Research 2020, 10, 39-47, http://dx.doi.org/10.5958/2231-5691.2020.00009.X.

16. Dahmash, M.T.R. Modified Drug Release Oral Solid Formulations of Floating Pellets, using Extrusion and Spheronisation Method. Doctoral dissertation, University of Sunderland 2020.

17. Rahim, S.A. Preparation and Characterisation of Floating Tablets to Target the Stomach. Doctoral dissertation, University of Sunderland 2018.

18. Zhang, M.; Yang, J.; Cai, Z.; Feng, Y.; Wang, Y.; Zhang, D.; Pan, X. Detection of Engineered Nanoparticles in Aquatic Environments: Current Status and Challenges in Enrichment, Separation, and Analysis. Environmental Science: Nano 2019, 6,709-735, https://doi.org/10.1039/C8EN01086B.

19. Nguyen, T.T.; Hwang, K.M.; Kim, S.H.; Park, E.S. Development of Novel Bilayer Gastroretentive Tablets based on Hydrophobic Polymers. International Journal of Pharmaceutics 2020, 574, https://doi.org/10.1016/j.ijpharm.2019.118865.

20. Qureshi, D.; Nayak, S.K.; Maji, S.; Kim, D.; Banerjee, I.; Pal, K. Carrageenan: A Wonder Polymer from Marine Algae for Potential Drug Delivery Applications. Current Pharmaceutical Design 2019, 25, 11721186, https://doi.org/10.2174/1381612825666190425190754.

21. Zahir-Jouzdani, F.; Wolf, J.D.; Atyabi, F.; Bernkop-Schnürch, A. In situ Gelling and Mucoadhesive Polymers: Why do They Need Each Other? Expert Opinion on Drug Delivery 2018, 15, 1007-1019, https://doi.org/10.1080/17425247.2018.1517741.

22. Rho, H.; Chon, K.; Cho, J. Surface Charge Characterization of Nanofiltration Membranes by Potentiometric Titrations and Electrophoresis: Functionality vs. Zeta Potential. Desalination 2018, 427, 19-26, https://doi.org/10.1016/j.desal.2017.11.003.

23. Leitner, S.; Solans, C.; García-Celma, M.J.; Caldero, G. Low-Energy Nano-Emulsification Approach as a Simple Strategy to Prepare Positively Charged Ethylcellulose Nanoparticles. Carbohydrate Polymers 2019, 205, 117-124, https://doi.org/10.1016/j.carbpol.2018.10.025.

24. Griesser, J.; Hetényi, G.; Federer, C.; Steinbring, C.; Ellemunter, H.; Niedermayr, K.; Bernkop-Schnürch, A. Highly Mucus Permeating and Zeta Potential Changing Self-Emulsifying Drug Delivery Systems: A Potent Gene Delivery Model for Causal Treatment of Cystic Fibrosis. International Journal of Pharmaceutics 2019, 557, 124-134, https://doi.org/10.1016/j.ijpharm.2018.12.048.

25. Mahdavinia, G.R.; Soleymani, M.; Etemadi, H.; Sabzi, M.; Atlasi, Z. Model Protein BSA Adsorption onto Novel Magnetic Chitosan/PVA/Laponite RD Hydrogel Nanocomposite Beads. International Journal of Biological Macromolecules 2018, 107, 719-729, https://doi.org/10.1016/j.ijbiomac.2017.09.042.

26. Noh, S.Y.; Nash, A.; Notman, R. The Aggregation of Striped Nanoparticles in Mixed Phospholipid Bilayers. Nanoscale 2020, 12, 4868-4881, https://doi.org/10.1039/c9nr07106g.

27. Singh, P.; Gilhotra, R.M. Formulation and Evaluation of Guar Gum based Matrix Tableted Glibenclamide Microspheres. International Journal of Research in Pharmaceutical Sciences 2020, 11, 2445-2457, https://doi.org/10.26452/ijrps.v11i2.2238.

28. Saravanakumar, K.; Thulluru, A.; Samineni, R.; Ishwarya, M.; Nagaveni, P.; Mahammed, N. Effect of Sodium Alginate in Combination with Natural and Synthetic Polymers on the Release of Verapamil HCL from its Floating Microspheres. Journal of Pharmaceutical Sciences and Research 2019, 11, 2028-2035.

29. Razdan, K.; Sahajpal, N.S.; Singh, K.; Singh, H.; Singh, H.; Jain, S.K. Formulation of Sustained-Release Microspheres of Cefixime with Enhanced Oral Bioavailability and Antibacterial Potential. Therapeutic Delivery 2019, 10, 769-782, https://doi.org/10.4155/tde-2019-0057.

30. Raval, M.; Bagada, H. Formulation and Evaluation of Cyclodextrin-Based Thermosensitive In Situ Gel of Azithromycin for Periodontal Delivery. Journal of Pharmaceutical Innovation 2019, 1-18, https://doi.org/10.1007/s12247-019-09422-3. 